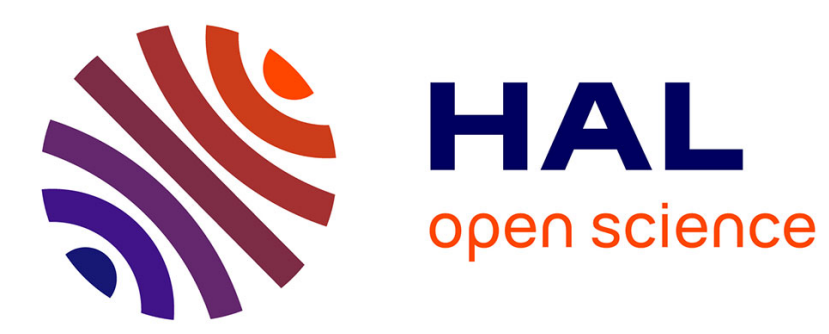

\title{
On truth unpersistence: At the crossroads of epistemic modality and discourse
}

\author{
Patricia Amaral, Fabio Del Prete
}

\section{To cite this version:}

Patricia Amaral, Fabio Del Prete. On truth unpersistence: At the crossroads of epistemic modality and discourse. Natural Language and Linguistic Theory, 2016, pp.1135-1165. 10.1007/s11049-0159325-5 . hal-01289163

\section{HAL Id: hal-01289163 \\ https://hal.science/hal-01289163}

Submitted on 16 Mar 2016

HAL is a multi-disciplinary open access archive for the deposit and dissemination of scientific research documents, whether they are published or not. The documents may come from teaching and research institutions in France or abroad, or from public or private research centers.
L'archive ouverte pluridisciplinaire HAL, est destinée au dépôt et à la diffusion de documents scientifiques de niveau recherche, publiés ou non, émanant des établissements d'enseignement et de recherche français ou étrangers, des laboratoires publics ou privés. 


\section{On truth unpersistence: at the crossroads of epistemic modality and discourse}

Patrícia Amaral and Fabio Del Prete

Indiana University and CLLE-ERSS (CNRS \& Université de Toulouse II)

Abstract We propose a semantic analysis of the particles afinal (European Portuguese) and alla fine (Italian) in terms of the notion of truth unpersistence, which combines both epistemic modality and constraints on discourse structure. We argue that the felicitous use of these modal particles requires that the truth of a proposition $p^{*}$ fail to persist through a temporal succession of epistemic states, where $p^{*}$ is incompatible with the proposition modified by afinal/alla fine, and that the interlocutors share knowledge of a previous epistemic attitude toward $p^{*}$. We analyze two main cases, that of plan-related propositions and that of propositions without plans. We also discuss the connections between truth unpersistence and evidentiality.

Keywords Epistemic modality; Discourse; Presupposition; Modal particles

\section{Introduction}

The adverb sempre 'always' in European Portuguese (henceforth, EP) and Italian can mean something quite different from a universal quantification over times (Gonzaga 1997; Brito 2001; Amaral and Del Prete 2014). ${ }^{1}$ Consider, for instance, (1a,b):

(1) a. Sempre vou ao cinema no domingo à noite. (EP) Sempre go-PRES-1SG to-the cinema in-the Sunday at night

b. $\quad$ Ci vado sempre al cinema domenica sera. (Italian) there go-PRES-1SG sempre to-the cinema Sunday night 'I'm sempre going to the movies this Sunday night.'

\footnotetext{
${ }^{1}$ We thank three anonymous reviewers, as well as the audiences of the workshop Pragmatic Markers, Discourse Markers and Modal Particles (Como, October 2014) and of the $45^{\text {th }}$ Linguistic Symposium on the Romance Languages (Campinas, May 2015). We would also like to thank Nicholas Asher, Luca Barlassina, Heather Burnett, Basilio Calderone, Julie Hunter, Fabio Montermini and Sandro Zucchi for comments and discussion. Any shortcomings are our own responsibility.
} 
These sentences could be felicitously uttered in the following situation, $\mathrm{S}_{0}$ : on Monday, I planned on going to the movies next Sunday night and told you about my plan; now it is Wednesday, the possibility that I might end up not going to the movies has become salient in our common ground and I want to reassure you that my plan continues to be valid. By uttering (1a,b) in $\mathrm{S}_{0}$, I confirm the truth of a proposition that had already been accepted as true by the two of us and has now become uncertain. Here, sempre does not universally quantify over times-(1a,b) do not mean that I go to the movies on every Sunday night - but rather expresses that a certain plan continues to be valid. Accordingly, the negation of $(1 \mathrm{a}, \mathrm{b})$ is not given by the temporal quantification 'Sometimes I don't go to the movies on Sunday night'. It has recently been proposed that sempre in such examples is a modal operator of "truth persistence", contributing the confirmation of the modified proposition (Amaral and Del Prete 2014).

In this paper, we consider a particular way to convey that the truth of a previously entertained proposition is disconfirmed, as shown by the following examples:

(2) a. Afinal não vou ao cinema no domingo à noite. (EP) Afinal not go-PRES-1SG to-the cinema in-the Sunday at night

b. Alla fine non ci vado al cinema domenica sera. (Italian) alla fine not cl go-PRES-1SG to-the cinema Sunday night 'Afinal/alla fine I'm not going to the movies this Sunday night.'

Sentences $(2 a, b)$ could be felicitously uttered in the following situation $S_{1}$, continuing $S_{0}$ : it is Saturday, I finally decide to abandon my plan to go to the movies on Sunday night and I want to tell you about my decision. By uttering $(2 \mathrm{a}, \mathrm{b})$ in $\mathrm{S}_{1}$, I express to you that I'm no longer committing myself to the truth of the proposition that I'll go to the movies on Sunday night.

Extending the above mentioned analysis of the meaning of sempre in $(1 \mathrm{a}, \mathrm{b})$ in terms of truth persistence, this paper proposes the notion of truth unpersistence (henceforth, $\sim \mathrm{TP}$ ) as relevant to the semantic analysis of afinal and alla fine in (2a,b). This notion captures a basic fact concerning felicitous and truthful utterances of $(2 \mathrm{a}, \mathrm{b})$ : they require that the truth of a proposition $p^{*}$ fail to persist through a temporal succession of epistemic states, where $p^{*}$ is incompatible

\footnotetext{
${ }^{2}$ Although most of the examples in the paper include a negation, this is not required by the semantics of the particles, as shown below by examples (3a,b).
} 
with the proposition modified by afinal/alla fine (hereafter, the "prejacent"). ${ }^{3}$ We will show that the notion of $\sim \mathrm{TP}$ is situated at the intersection of modality and discourse structure. On the one hand, the modal character of the notion will be apparent from considering that $\sim \mathrm{TP}$ refers to those semantic entities that are the bearers of truth values, i.e., propositions; more precisely, TP requires that a proposition's truth value be assessed relative to the possible worlds in a certain epistemic space. On the other hand, the relevance of $\sim \mathrm{TP}$ to the study of discourse will be made clear by the examples presented; these show that afinal and alla fine have strong contextual effects, in that they impose constraints on the possible discourse contexts in which they may felicitously occur-as a consequence, in order to grasp their interpretation, one must have access to discourse information coming from preceding utterances. The above description of the conditions of use of (2a,b) already shows that the use of afinal and alla fine in those examples require that the interlocutors share knowledge of a previous epistemic attitude-indeed, their own-toward a certain proposition $p^{*}$. We will see that sentences containing afinal/alla fine are well attested in conversational exchanges, and even when found in narratives, they arguably occur in dialogic contexts. This shows that $\sim \mathrm{TP}$ has an interactional nature.

The structure of the paper is as follows. In sections 2 and 3, we present the empirical data from European Portuguese and Italian. The data reveal that EP afinal and Italian alla fine are epistemic markers of $\sim$ TP. In addition, alla fine has a use in which it conveys both the temporal meaning 'at the end of $\mathrm{X}$ ' and $\sim \mathrm{TP}$ of a proposition, the latter component arising as an inference. In section 4, we review a previous proposal regarding the interpretation of afinal in EP and compare it to our analysis. In section 5, we extend the proposal in Amaral and Del Prete (2014) for a modal analysis of the meaning of sempre in $(1 \mathrm{a}, \mathrm{b})$ to the meaning of alla fine and afinal in sentences like (2a,b), to provide a formal account based on the notion of $\sim$ TP. Section 6 concludes by outlining some of the consequences of our analysis and pointers for future work.

\section{The TP value: Empirical data from EP and Italian}

First, we consider two kinds of cases that need to be accounted for (sections 2.1 and 2.2), highlighting the presuppositional character of afinal/alla fine and their semantic contribution as markers of epistemic change. Then, we examine the role of afinal/alla fine as epistemic markers

\footnotetext{
${ }^{3}$ The notion of incompatibility that is relevant for the semantics of these particles will be detailed in section 2 .
} 
and their presuppositional behavior in more detail, by looking at naturally-occurring data (sections 2.3 and 2.4).

\subsection{Plan-related propositions}

We start with the case of an assertion by which the speaker communicates to the hearer that a certain plan, which she had previously entertained and shared with him, is not valid anymore.

Suppose that we are talking about what leisure activities we might partake in tonight, following up on a conversation we had last week. During our past exchange, you had told me that you would go to the theater tonight, and what is recalled at present is precisely this old plan. In the meanwhile, however, you have changed your mind, as you have come to know of a good movie which interests you more. Given this scenario, you utter one of (3a,b):
a. Afinal hoje vou ao cinema.
b. Alla fine vado al cinema questa sera.
'Afinal/alla fine I'm going to the movies tonight.'

Notice that, for (3a,b) to be acceptable in the depicted conversational context, the following conditions must be satisfied:

(C1) the speaker had planned on going to some place, different from the movie theater;

(C2) the speaker shared with the hearer the information that she had planned on going to this other place. ${ }^{4}$

Provided that conditions (C1) and (C2) are satisfied, (3a,b) are true if and only if the speaker's old plan to go to the theater is no longer valid at the time of utterance. If (C1) and (C2) are not jointly satisfied, uttering (3a,b) results in infelicity.

\footnotetext{
${ }^{4}$ Given conditions (C1) and (C2), it is more natural to have a positive rather than a negative proposition in the role of the shared proposition $p^{*}$ since people usually don't entertain negative plans or say what they are not going to do. Arguably, this would not be informative, because we are generally more interested in what people are going to do rather than in what they are not going to do. On the other hand, it is perfectly natural to have a negative proposition as the prejacent of alla fine/afinal. For example, the speaker of (3a,b) might equally well utter (ia, b):

(i) a. Afinal hoje não vou ao teatro.

b. $\quad$ Alla fine non vado a teatro questa sera.

'Afinal/alla fine I'm not going to the theater tonight.'
} 
Crucially, if we remove the expressions alla fine/afinal from (3a,b), we obtain sentences that do not trigger the contextual effects (C1) and (C2). For instance, the EP sentence hoje vou ao cinema 'I'm going to the movies tonight' can be felicitously uttered to inform the hearer that going to the movies is a plan of the speaker, as in the following exchange:
A. Hoje à noite vamos ao teatro?
'Shall we go to the theater tonight?'
B. Lamento, mas não posso. Hoje vou ao cinema.
'Sorry I can't. I'm going to the movies tonight.'

It should be obvious that in this case, before B's utterance, no information was shared between A and B concerning B's plan to go to the movies tonight.

Yet another example of the same kind as (3a,b), in which the relevant plan is not one of the speaker but is authored by a third party-an institution with planning powers - is the following. Suppose that, after running a worldwide boycott, a group of activists campaigning against the organization of the 2016 Rio de Janeiro Olympics manage to obtain the change of the host city for this event. After the change, one could felicitously and truthfully utter one of (4a,b):
a. Afinal os Jogos Olímpicos de 2016 não vão ser no Rio de Janeiro
b. $\quad$ Alla fine le Olimpiadi 2016 non si terranno a Rio de Janeiro.
'Alla fine the 2016 Olympics won't take place in Rio de Janeiro.'

For an utterance of $(4 \mathrm{a}, \mathrm{b})$ to be felicitous, conditions similar to (C1) and (C2) above have to be satisfied, namely:

(C1') a relevant subject had planned that the 2016 Olympics would be held in Rio de Janeiro;

(C2') that subject shared with the interlocutors of $(4 a, b)$ the information that it had planned that the 2016 Olympics would be held in Rio de Janeiro.

That failure to satisfy these conditions would result in infelicity is clear from considering the status of an utterance of (5) (the same judgment applies to the corresponding example of EP): 
(5) \#Alla fine le Olimpiadi 2016 non si terranno a Roma.

'Alla fine the 2016 Olympics won't take place in Rome.'

It would be infelicitous for anyone in 2015 to utter (5), since it has never been planned and made public that the 2016 Olympics would take place in Rome.

Again, if we remove the expressions alla fine/afinal from (4a,b), we obtain sentences that do not trigger the contextual effects ( $\left.\mathrm{C} 1^{\prime}\right)$ and (C2'). For instance, the Italian sentence le Olimpiadi 2016 non si terranno a Rio de Janeiro 'the 2016 Olympics won't take place in Rio de Janeiro' could be felicitously uttered in a non-actual context to inform the hearer that the 2016 Olympics' taking place in Rio is not a plan which is entertained, as in the following imaginary exchange:

A. Ho sentito che c'è stato un meeting del Comitato Olimpico Internazionale stamane. Vorrei tanto che le Olimpiadi 2016 si tengano a Rio de Janeiro! 'I heard that there was a meeting of the International Olympic Committee today. I would very much like that the 2016 Olympics took place in Rio de Janeiro!’

B. Mi dispiace per te... le Olimpiadi 2016 non si terranno a Rio. Il Comitato ha deciso che si terranno a São Paulo.

'I'm sorry for you... the 2016 Olympics won't take place in Rio. The Committee has decided that they will take place in São Paulo.'

Negative utterances too trigger contextual effects, often treated as presuppositional (Givón 1989, Horn 1989). Thus, in the exchange in (6), A's utterance implicitly raises the possibility-call it $p$-that the 2016 Olympics take place in Rio de Janeiro, and in the resulting context, B's negative utterance informs $A$ that the International Olympic Committee has decided that they will take place in São Paulo, thereby excluding $p$. If $p$ had not been raised to salience before B's negative utterance, the latter would have been infelicitous. However, the contextual effects triggered by afinal and alla fine are different: indeed, in the context of (6), the proposition that the 2016 Olympics will take place in Rio de Janeiro was not shared knowledge between the interlocutors before B’s negative utterance. 


\subsection{Propositions without plans}

The second case that we consider is one in which the speaker and the hearer had first shared the belief that a certain proposition $p^{*}$ was true, and now they have changed their epistemic attitude toward $p^{*}$ as they have come to believe, on the basis of new evidence, that $p^{*}$ is false.

Suppose that you and I have thus far shared the false belief that our neighbor Micha is Russian, since we have been misled by his name. Today I see his passport and I learn that he is actually Ukrainian, so I change my previous belief about Micha's nationality on the basis of the more reliable source of information. As I change my belief, I can felicitously utter one of $(7 \mathrm{a}, \mathrm{b})$ :
a. Afinal o Micha não é russo, é ucraniano.
b. Alla fine Micha non è russo, è ucraino. ${ }^{5}$
'Afinal/Alla fine Micha is not Russian, he’s Ukrainian.'

The utterance of (7), besides conveying that an epistemic change has occurred, also has an evidential flavor, in that it suggests that the final belief is grounded in a better source of evidence than the initial one (possibly a direct source).

Yet another case, in which the proposition which is first believed and then disbelieved is about a past event, is the following. Suppose that you and I share the false belief that our friend João, who we know was involved in a car accident, died, since we have misunderstood certain confused testimonies. Today I see a common friend and I learn that João is actually alive, so I change my previous belief about João's condition on the basis of the more reliable source of information. As my belief changes, I can felicitously utter one of (8a,b):

$$
\begin{aligned}
& \text { a. Afinal o João não morreu, ficou apenas ferido. } \\
& \text { b. Alla fine João non è morto, è solo ferito. } \\
& \text { 'Afinal/Alla fine João did not die, he is only wounded.' }
\end{aligned}
$$

\footnotetext{
${ }^{5}$ In Italian, the adverb poi 'then' can be used in combination with alla fine to reinforce the effect of the latter, as in, e.g., Alla fine poi Micha non è russo. In this function, poi can co-occur with alla fine also when the prejacent is planrelated, as shown by the possibility of saying Alla fine poi non ci vado al cinema domenica sera or Alla fine poi le Olimpiadi 2016 non si terranno a Rio de Janeiro (we thank Andrea Bonomi for calling our attention to this interpretation of poi). It is interesting to remark that expressions related to temporal language, in particular to the concept of temporal succession, systematically take on the non-temporal meaning of unpersistence of truth. In this regard, one may point to a semantic similarity between alla fine, on the one hand, and expressions like dopo tutto 'after all' and in fin dei conti 'after all is said and done' (lit. 'at the end of the sums'), which can also be found in contexts of $\sim \mathrm{TP}$.
} 
These sentences too display an evidential flavor.

Notice that, for $(7 \mathrm{a}, \mathrm{b})$ and $(8 \mathrm{a}, \mathrm{b})$ to be acceptable in their contexts, the following conditions must be satisfied:

(C3) the speaker had the belief that a certain proposition $p^{*}$ (that Micha is Russian, that João died) was true;

(C4) she shared the belief that $p^{*}$ was true with the hearer.

Provided that conditions (C3) and (C4) are satisfied, (7a,b) and (8a,b) are true if and only if the speaker's old belief is no longer valid at the time of utterance. If (C3) and (C4) are not jointly satisfied, uttering $(7 \mathrm{a}, \mathrm{b})$ and $(8 \mathrm{a}, \mathrm{b})$ results in infelicity.

Importantly, if we remove the expressions alla fine/afinal from (7a,b) and (8a,b), we obtain sentences that do not trigger the contextual effects (C3) and (C4). For example, the sentence Micha non è russo could be felicitously uttered to inform a hearer misguided by deceptive evidence that Micha is not Russian, as in the following exchange:

(9) A: Dai suoi tratti e dal suo accento, mi sembra che Micha sia russo.

'From his traits and accent, it seems to me that Micha is Russian.'

B: $\quad$ No. Micha non è russo. È ucraino.

'No. Micha is not Russian. He’s Ukrainian.'

Clearly, in this case there is no old belief about Micha being Russian which was shared by the interlocutors before B's utterance.

There is an additional difference between examples (7) and (8), on the one hand, and (9), on the other. Imagine that B has excluded Micha's Russian origin because he knows the Russian accent well. While it would be fine for B to continue his response in (9) with the sentence in (9'), such a continuation would not be acceptable for a sentence containing afinal/alla fine.

(9') B. Però per essere sicuro voglio vedere il suo passaporto. Forse è georgiano.

'But to be sure I want to see his passport. Maybe he is Georgian.' 
The use of afinal/alla fine signals that the sentence containing the particle refers to an epistemic state which is treated as final with respect to an ongoing discussion-in other terms, the epistemic state in question obtains at the final point of the time interval during which the discussion takes place. Hence, it is infelicitous to provide a discourse continuation indicating that the speaker might change his mind again in the future and trigger an information update. This property of afinal/alla fine shows the intricate connection between its modal, evidential and discourse nature. We can hypothesize that this constraint on possible continuations is a remnant of the lexical meaning of the noun for 'end' present in the etymon of the particles, which has now become a constraint on their use in discourse. ${ }^{6}$ The relation between the temporal order on time points relevant for the interpretation of afinal/alla fine and the induced order on epistemic states will be detailed in the formal analysis (section 5).

A related issue is that of the evidential flavor that we have found in (7) and (8): is this flavor semantically encoded by afinal/alla fine, or is it an inference arising from the fact that the speaker has changed his mind, hence implicating that the new source of information that determines the change is more reliable than the previous one? Although it may not be a priori clear what the right answer is, there are empirical reasons to believe that the evidential flavor is not semantically contributed by the particles. Indeed, the contribution of afinal/alla fine to the sentence meaning is intuitively the same in (3)-(4) and (7)-(8), namely, that of a TP marker; still, the evidential aspect is only found in (7)-(8), i.e. when the prejacent is a non plan-related proposition. This difference may be tentatively explained by arguing that, in the case of planrelated prejacents, the change affects a type of propositional attitude (i.e., decision) which is not grounded in evidence in the same way as beliefs are. While the change of our belief concerning Micha's nationality or João's having died is naturally triggered by the availability of a better type of evidence, the change of plans from going to the theater to going to the movies or from hosting the Olympics in Rio de Janeiro to hosting them elsewhere is not due to the availability of better evidence in the same way. We will leave the explanation of the evidential property of (7)-(8) and

\footnotetext{
${ }^{6}$ We are grateful to an anonymous reviewer for making this connection apparent to us. The feature of alla fine and afinal which constrains the possible discourse sequences and excludes continuations that "open up" the issue again which had been closed by the afinal statement could be seen as an instance of a general principle of grammatical change. In the literature on syntactic and semantic change, this is known as "persistence” (Hopper 1991), a principle by which aspects of the lexical meaning of the source lexical item that underwent change may impose constraints on the distribution of the reflex.
} 
the difference with respect to (3)-(4) as a speculation here and we will return to the connection between modality, evidentiality, and discourse structure in section 6.

To sum up, the data presented in this section and the previous one show that, for an utterance of afinal/alla fine $(p)$ to be felicitous, an appropriate epistemic attitude toward a proposition $p^{*}$ incompatible with $p$-either a belief that $p^{*}$ is the case or an expectation that $p^{*}$ will be the case-must have been jointly held by the speaker and the hearer. ${ }^{7}$ This is illustrated by the diagram in Fig. 1, where $\Omega(\operatorname{int}(C), t)$ is the epistemic state of the interlocutors of context $C$ at time $t$, the time points $t^{*}<t_{i}<t_{j}<t_{\text {end }}$ are ordered on the time line from earlier to later, inducing a similar order on the corresponding epistemic states, the time interval $\left[t^{*}, t_{\text {end }}\right]$ corresponds to the discussion or discourse sequence which is relevant for the interpretation of the utterance, a proposition $p$ situated below a time point $t$ is part of the corresponding state $\Omega(\operatorname{int}(C), t)$, and $\sim p^{*}$ is a proposition incompatible with $p^{*}$ and need not have the form of the logical negation of $p^{*}$ :

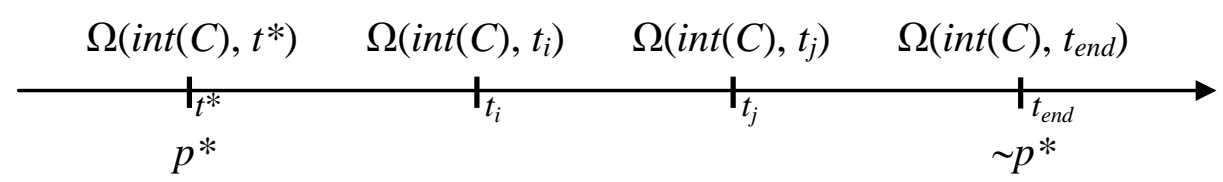

Fig. 1 Felicity conditions of afinal/alla fine $\left(\sim p^{*}\right)$

Moreover, we have seen that the requirement of a previous shared epistemic attitude is a condition imposed on the context by afinal/alla fine, since failure to satisfy it results in an infelicitous utterance. On this basis, we draw the following conclusions:

- Epistemic change

Sentences containing afinal and alla fine introduce epistemic change of an agent.

- Presuppositionality

The use of afinal and alla fine is presuppositional.

\footnotetext{
${ }^{7}$ In the next sections we will consider newspaper examples with afinal/alla fine showing that the speaker and hearer's epistemic attitudes need not be concerned, as other epistemic agents become relevant.
} 
We develop each of these points in the next two sections.

Before concluding this section, let us pause on the relevant notion of incompatibility. When we say that proposition $p^{*}$ is "incompatible" with the prejacent of afinal, we do not mean that the prejacent and $p^{*}$ are logically incompatible, but rather that the factual realization of one proposition excludes the factual realization of the other. The situation in which there is logical incompatibility_e.g. with the prejacent having the form of the logical negation of $p^{*}$ —is only a special case of the general relation. We will capture this property in the formal analysis in section 5 by taking propositions to be temporally specific.

\subsection{Epistemic change}

We have seen in sections 2.1 and 2.2 that a sentence of the form afinal/alla fine(p) presupposes a previous shared epistemic attitude toward a proposition $p^{*}$ incompatible with $p$ and implies that this attitude does not hold at present. Therefore, such a sentence encodes an epistemic change: in the case of plan-related propositions, the change affects the plan as well as the interlocutors' beliefs about it; in the case of propositions that are not plan-related, the change pertains to the truth value of a proposition as evaluated by an agent at successive times, presumably on the basis of new incoming evidence. We have also seen that it is arguably the particles afinal/alla fine that contribute to the encoding of the change.

This property of afinal and alla fine is revealed by a specific linguistic pattern: sentences containing these particles can be paraphrased by embedding the prejacent of afinal/alla fine under a predicate expressing epistemic change, as shown by the constructed examples (10a,b): ${ }^{8}$

\footnotetext{
${ }^{8}$ The syntactic position of afinal and alla fine with respect to the predicate expressing epistemic change (above or under the latter) is irrelevant in this respect: the interpretation obtained is the same. For example, we can detect no difference in meaning between the naturally-occurring discourse (i) and its variant (ii):

(i) Correre senza il mio fedele [...] garmin inizialmente mi aveva smarrito, senza un riferimento, andatura, tempo, km percorsi... poi invece, ho scoperto che alla fine non è così essenziale, si può far benissimo senza.

'Running without my trustworthy garmin at first had got me lost, without a reference, pace, time, covered distance... but then I discovered that alla fine it is not so essential, one can well do without it.' (http://sergiosambataro.blogspot.fr/2012/03/la-mia-prima-maratona.html)

(ii) [...] poi invece, alla fine ho scoperto che non è così essenziale, si può far benissimo senza.
}

The examples presented in this section show both possibilities. 
(10) a. Alla fine ho scoperto/capito che Micha non è russo.

'Alla fine I discovered/understood that Micha is not Russian.'

b. Alla fine ho deciso che non vado a teatro questa sera.

'Alla fine I decided that I won't go to the theater tonight.'

In (10a), the sentence Micha non è russo 'Micha is not Russian' is implied by the embedding predicate scoperto/capito to express a new belief of the speaker; furthermore, this belief is presented as reflecting a change with respect to a previous shared belief, i.e. the belief that Micha is Russian. Analogously, in (10b), the sentence non vado a teatro questa sera 'I won't go to the theater tonight' is implied by the embedding predicate deciso to express a new epistemic state of the subject of the plan (the speaker in this case), and this state is presented as reflecting a change with respect to a previous plan, information about which was previously shared between the interlocutors. Note that the difference between the two cases cannot be subsumed under a distinction between present and future, as made apparent by (11):

(11) Afinal (parece que) não vai chover amanhã.

'Afinal it appears that it won't rain tomorrow.'

In (11), the proposition that it will not rain tomorrow is evaluated with respect to the future but is not plan-related. Rather, the change encoded by afinal in this case pertains to a belief about a worldly event, and it presumably follows from the agent's receiving more reliable evidence to the effect that it will not rain tomorrow.

In naturally-occurring examples of EP (with propositions that are not plan-related), we find occurrences of afinal either under epistemic predicates (e.g. pensar 'to think', or achievement verbs denoting a change of state like descobrir 'to discover', ficar a saber 'to find out') or in contexts in which different beliefs, entertained at different times, are explicitly contrasted. Here we consider some examples from newspapers' articles involving the verb descobrir and an inchoative interpretation of saber ('to come to know'). The examples, given in (12) and (13), show how shared knowledge and belief states are introduced in the context and provide the complex background information required to interpret sentences with afinal. 
(12) Há cinco meses, também se pensou que a Irlanda tinha escolhido uma saída limpa. Só algumas semanas mais tarde é que se descobriu que Dublin afinal não pôde escolher; tal como em Portugal lhe foi imposta uma saída sem rede. ${ }^{9}$

'Five months ago, we also thought that Ireland had chosen a clean exit [from the financial rescue plan]. Only some weeks later did we discover that Dublin afinal couldn't choose; as was the case for Portugal, Ireland was forced to adopt an exit with no security.'

(13) Wayne fica desbaratinado quando sabe que Tick afinal não é seu filho. ${ }^{10}$

'Wayne loses it when he finds out that Tick afinal is not his son.'

In (12), afinal marks $\sim$ TP of the proposition $p^{*}$ that Ireland had the possibility to choose a clean exit from the financial rescue plan. The succession of times associated with the different belief states that are reported pertains to a set of agents G, which represents the general public; TP of $p^{*}$ obtains at a time which is posterior to the moment at which $p^{*}$ was believed to be true by members of G. In (13), what licenses the use of afinal is the fact that Wayne first believes that Tick is his son, and then changes his belief as he comes to know that Tick is not his son. Another important feature of (13) is that it involves a shift of perspective from the author of the text to Wayne, as in cases of so-called "free indirect discourse". This has an important consequence: even though Wayne is not the author of the text, and thus not one of the interlocutors involved in the "utterance" of (13), the relevant perspective for the evaluation of (13) - in particular, of that part of (13) which is interpreted in the scope of afinal-is Wayne's, as if he were the speaker uttering the words Tick afinal não é meu filho 'Tick afinal is not my son'.

Summing up, the examples presented in this section show that the notion of $\sim \mathrm{TP}$ of a proposition $p^{*}$ can only be assessed with respect to a group of epistemic agents $G$ and a succession of times, i.e. what matters for the evaluation of afinal/alla fine( $p)$ is not the truth value of $p^{*}$ in the actual world at the time of speech, but rather the evaluation of $p^{*}$ by the agents in $\mathrm{G}$ at successive times. Hence, the $\sim \mathrm{TP}$ value of afinal and alla fine requires that we consider the notion of truth of a proposition not as absolute truth but rather as truth relative to epistemic agents at different points in time.

\footnotetext{
${ }^{9}$ From the newspaper Público, Editorial, 5/5/2014.

${ }^{10}$ From the corpus CETEMPúblico, par=ext8453-soc-91b-1.
} 


\subsection{Presuppositionality}

We now look at the presuppositional character of afinal and alla fine more closely. As is often the case with presupposition, the licensing conditions for the trigger can be complex and involve a range of discourse-pragmatic factors (cf. Stalnaker 1974, among many others). As we will see in this section, the proposition $p^{*}$ may or may not be present in the common ground. In the case in which $p^{*}$ is not present in the common ground, it can be inferred from a proposition in the common ground, it can come from world-knowledge, or it can be reconstructed locally. ${ }^{11}$

If we look at corpus data, we find that the presupposition of an epistemic change that is triggered by afinal/alla fine is sometimes explicitly satisfied in the text, as the author first reports someone as saying that $p$, and then informs that $p$ turns out to be false. This is what happens in (14):

(14) Lui [Henry Hill], un po' intimidito in effetti, chiede attraverso l'interprete se "può essere incriminato". "Per quello che ha già detto negli Stati Uniti, no", spiega il presidente. "Allora ripeterò quello che ho già detto là", replica pronto Hill. Rumoreggiano i difensori [di Michele Sindona e Robert Venetucci]: “Allora ce ne andiamo a casa tutti”. Alla fine non se ne va nessuno, e cominciano le domande. ${ }^{12}$

'A little bit intimidated, he [Henry Hill, the accused] asks through the interpreter whether "he may be incriminated". "For what you have already said in the United States, you may not”, explains the president. "In this case, I'll repeat what I have already said there”, Hill quickly replies. The defense attorneys [of Michele Sindona and Robert Venetucci] rumble: "If this is the case, we'll all go home". Alla fine nobody leaves, and the questions begin.'

The proposition of which alla fine marks $\sim \mathrm{TP}$ is the one expressed by the sentence embedded under the verb of saying rumoreggiare 'to rumble': the proposition that all defense attorneys

\footnotetext{
${ }^{11}$ This complex property of the presuppositional antecedent $p^{*}$ may be thought of in terms of Zeevat's (2009) notion of weak presupposition, which Zeevat regards as unavoidable for the analysis of discourse particles, in particular correction markers (to whose class afinal and alla fine may be plausibly ascribed). According to this author, "the weak presupposition may be in the common ground as such, but it can equally well be in the common ground as a suggestion, as an opinion of somebody or merely as a plausible inference" (Zeevat 2009: 127). We thank an anonymous reviewer for calling our attention to Zeevat's work.

${ }^{12}$ From the newspaper La Repubblica, October $22^{\text {nd }} 1985$ (http://ricerca.repubblica.it/repubblica/archivio/repubblica/1985/10/22/si-arico-ha-assassinato-ambrosoli.html).
} 
leave the courtroom (at the relevant time during the trial). This example is dialogic, as it reports contrasting points of view: on the one hand, we have the reported point of view of the defense attorneys who are "rumbling” that they will go home if the accused repeats what he has already said in the United States; on the other hand, we have the point of view of the author of the article, who comments that eventually nobody leaves (that is, no one of the defense attorneys leaves the courtroom at the relevant time during the trial). The proposition that is truth unpersistent is the proposition that all defense attorneys leave the courtroom. Therefore, the relevant sense of “dialogic" does not require an actual conversation, of which the speaker using alla fine would be a participant. ${ }^{13}$ Rather, it requires the existence of different epistemic states pertaining to different epistemic agents - in the case at hand: the group of the defense attorneys and a larger group of agents attending the trial (and, perhaps, the author of the article as well, with his external perspective on the events of the trial). Hence, our presuppositions are conditions on the discourse structure, i.e. on discourse information originating from previous epistemic agents as actual or potential utterance participants. That is to say, the felicitous use of these particles requires a certain exchange between the interlocutors, where this exchange could have taken place among a whole community, as in example (12). The relevant notion of presupposition is different from the classic one, as it applies e.g. to the case of definite descriptions, amply discussed in the literature. For example, it is well known that the presupposition of a definite description occurring in the consequent of a conditional can be satisfied in a derived common ground, one which is obtained by adding the content of the if-clause to the initial common ground. This can be shown by the felicity of (15) in a context in which the interlocutors do not know whether John and Mary had an argument last night:

(15) If John and Mary had an argument last night, their argument was heard by their neighbors.

This is in sharp contrast with the behavior of the presuppositions of alla fine/afinal, as shown by the unacceptability of (16):

\footnotetext{
${ }^{13}$ Our sense of dialogic is close in spirit to the notion of "polyphonie" proposed by Anscombre and Ducrot, see Ducrot (1984).
} 
\#Se Gianni e Maria hanno discusso su dove andare, alla fine hanno preso una decisione. 'If Gianni and Maria have debated where to go, alla fine they have taken a decision.'

Here, "presupposition satisfaction” does not pertain only to a shared common ground, but rather to a dialogic common ground, i.e. one which is created by an interaction. The content of the ifclause cannot provide that dialogic common ground.

In other naturally-occurring examples, the epistemic change presupposed by afinal and alla fine can be inferred from the text but is not explicitly represented in it. In the examples below from Italian, the proposition $p^{*}$ that is truth unpersistent is not expressed by any sentence occurring in the text. For instance, in (17) the sentence containing alla fine is discourse-initial. Therefore, $p^{*}$ cannot be found in the previous discourse but is rather a general assumption from world knowledge that can be taken for granted or presupposed: ${ }^{14}$ the assumption that it is rare or strange to fall in love with a voice.

(17) Innamorarsi di una voce (specie se è quella di Scarlett Johansson) non è alla fine una cosa rara, ma se dietro quella voce non c'è uno straccio di corpo il fatto è diverso. ${ }^{15}$

'To fall in love with a voice (especially if the voice is that of Scarlett Johansson) is not alla fine a rare event, but if beyond the voice there is not a shred of a body, the matter is different.'

The felicity of the use of alla fine in (17) relies on the ability to accommodate ${ }^{16}$ the presupposition that falling in love with a voice is rare. The author of the text can reasonably assume that everybody believes this to be the case, that is, this proposition is treated as shared knowledge - as if a tacit conversation between the interlocutors had taken place before the utterance of (17).

\footnotetext{
${ }^{14}$ A similar description is provided for some uses of afinal: “ p peut également correspondre à une attente (ou croyance) de la communauté” (Lopes 2011: 135, footnote 3).

${ }^{15}$ From the newspaper Il Cittadino, March $3^{\text {rd }} 2014$ (http://www.ilcittadino.it/p/notizie/cultura_e_spettacoli/2014/03/03/ABlv3dsD-italia_ramazzotti_marzo_voce.html). ${ }^{16}$ Spenader (2002) shows that in naturally-occurring texts it is quite common for the use of presupposition triggers to involve accommodation.
} 
In yet other cases, the epistemic change seems to be from a state in which a question is entertained to a state in which a particular possibility is chosen to resolve the question. ${ }^{17}$ To exemplify, suppose that a family has considered a number of alternative plans for vacation, namely, going to the seaside, going to the mountains, and going to Rome. After debating the issue for a while, they choose going to the seaside, to the exclusion of the others. In this context, after the decision has been made, one member of the family can felicitously utter (18):

Alla fine quest'estate andiamo al mare.

'Alla fine, this summer we go to the seaside'

In this case, there was no previous belief implying that the family would not go to the seaside. Hence, an epistemic change from a proposition $p^{*}$ to another proposition incompatible with it (which was represented in Fig. 1 above) might seem unmotivated here. Rather, (18) appears to presuppose that the question Where are we going for vacation this summer? was under discussion at some point, with alla fine marking an epistemic change through which that question has been resolved.

One may thus argue that (18) is essentially different from the examples discussed above: these were shown to presuppose a previous attitude toward a proposition $p^{*}$, while the question apparently presupposed by (18) does not have a proposition as its meaning. Notice, however, that questions can be treated as disjunctions that present mutually exclusive alternatives, as has been emphasized by work in Inquisitive Semantics (Groenendijk and Roelofsen 2009, a.o., building on the groundbreaking work of Groenendijk and Stokhof 1984). We will follow this insight and, accordingly, see examples like (18) as involving a change from an epistemic state where mutually exclusive alternatives $p_{1}, \ldots, p_{\mathrm{n}}$ are under consideration, and each one is entertained as an open possibility, to an epistemic state in which one of $p_{1}, \ldots, p_{\mathrm{n}}$ is finally chosen to the exclusion of the others. One way to think about this change, in terms of a transition between incompatible propositions, is by instantiating the $p^{*}$-antecedent of (18) to the modal proposition that we may go to Rome this summer; this ends up being defeated by the proposition that we will

\footnotetext{
${ }^{17}$ We thank two anonymous reviewers for bringing this type of examples to our attention.
} 
not go to Rome this summer, which is an implication of the prejacent of alla fine in (18). ${ }^{18}$ In other words, we can look at the process leading to the utterance of (18) as a temporal succession of epistemic states: in the initial state the family thought that they may go to Rome, and in the final state they think that they will go to the seaside instead. This process can be depicted as in Fig. 2 (" $\diamond P($ Rome)" translates the proposition that we may go to Rome this summer and " $P$ (sea)" the prejacent of alla fine, i.e. the proposition that we go to the seaside this summer):

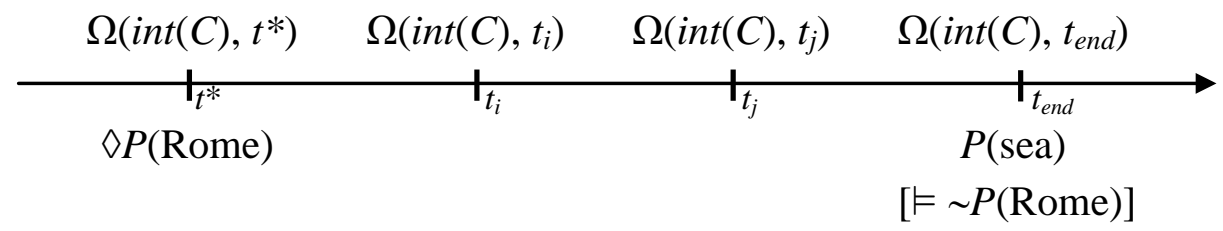

Fig. 2 Felicity conditions of (18)

We note that examples like (18) do not belong in either of the previous categories described in sections 2.1 and 2.2. On the one hand, propositions of the form $x$ may do $y$, being future-oriented, might seem to pattern like plan-related propositions. On the other hand, unlike propositions of the form $x$ will do $y$, they are not suitable to express an actual plan of $x$. Notice that in plan-related propositions one may have the aspectual particles já não/non più 'no longer' co-occurring with afinal/alla fine, as in Afinal hoje já não vou ao teatro/Alla fine non vado più a teatro questa sera 'Afinal/alla fine I'm no longer going to the theater tonight'. This is not possible in example (18), as uttered in the context described above: it would not be acceptable to say Alla fine quest'estate non andiamo più a Roma with the intended interpretation. Example (18) cannot be seen as involving a non plan-related prejacent either. As we saw in section 2.3, when the prejacent is non plan-related, one may embed it under a predicate of epistemic change meaning 'discover' or 'find out', e.g. Afinal descobri que o Micha não é russo 'Afinal I found out that Micha is not Russian'. This is not possible with (18), as uttered in the context described above: it would not be acceptable to say Alla fine abbiamo scoperto che andiamo al mare quest'estate (with the intended interpretation). Therefore, the attitude that we are concerned with in this example is not a belief.

\footnotetext{
${ }^{18}$ Note that the alternative possibilities are mutually exclusive; the fact that there was debating entails that the other possibilities were incompatible with the possibility of going to the seaside this summer (regardless of which of those other possibilities is selected to instantiate $p^{*}$, it will clash with the prejacent of alla fine).
} 
In this section, we have presented the empirical data and have focused on the similarities between EP and Italian. The next section considers a difference between the two languages with respect to these particles.

\section{TP inferences associated with temporal uses of alla fine}

In this section, we consider some prima facie cases of $\sim \mathrm{TP}$ value of alla fine which are characterized by the presence of a temporal process: a narration of a sequence of events is given in the text, which invites the inference that a certain proposition $p^{*}$ should be true, and a sentence of the form alla fine $\left(\sim p^{*}\right)$ occurs at the end of this narration, to counter this inference. As shown below, alla fine is not translatable as afinal in these cases, but rather as the adverbial no fim 'at the end'. We argue below that these cases are instances of the temporal adverbial alla fine 'at the end', with the TP component in the interpretation of the relevant examples being licensed as an inference by virtue of pragmatic reasoning.

One case in point is the naturally-occurring example (19):

(19) Nei mesi scorsi i ministri economici hanno dedicato gran parte del loro tempo a disputare sulla utilizzazione e la destinazione di quei 10 - 15 mila miliardi che si prevedeva di risparmiare in corso d'anno in forza dell'andamento dei mercati del petrolio e del dollaro. Da un lato, chi li voleva tutti trasferiti a vantaggio dei consumatori e delle imprese. Dal lato opposto, chi li voleva requisire a favore del contenimento del disavanzo pubblico. In mezzo, chi era per una soluzione mista. Alla fine non si è giunti a nessuna decisione strategica, ci si regolerà cammin facendo. ${ }^{19}$

'In the last months the ministers of economy have devoted a large part of their time to debate the use and destination of those 10 - 15 thousand billions that were predicted to be saved during the year as a consequence of the trend in the oil and dollar markets. On the one hand, some wanted to use them all in the interest of customers and companies. On the other hand, others wanted to use them to reduce the public debt. In the middle, yet others were for a mixed solution. Alla fine no strategic decision was reached, and things will be regulated as the process advances.'

\footnotetext{
${ }^{19}$ From the newspaper corpus La Repubblica.
} 
Intuitively, the use of alla fine in (19) requires a sequence of events (several attempts to find a strategic solution), and alla fine marks the endpoint of this sequence as a point at which something does not obtain (no strategic decision is reached then). Importantly, the conditions of use for alla fine illustrated by (19) are incompatible with the use of afinal, as shown by the unacceptability of (20a) below, which corresponds word-by-word to the relevant discourse segment in (19). Additionally, (20a) contrasts with (20b), which features the temporal adverbial no fim. $^{20}$

(20) a. Os ministros discutiram durante horas o que fazer com o dinheiro da União europeia, \# mas afinal não chegaram a nenhuma conclusão.

b. Os ministros discutiram durante horas o que fazer com o dinheiro da União europeia, mas no fim não chegaram a nenhuma conclusão.

'The ministers have debated for hours about what to do with the EU funds, but at the end (of the debate) they haven’t reached any conclusion.'

We argue that (19) is an instance of the temporal adverbial alla fine, as can be shown by morphosyntactic tests. As a temporal adverbial, alla fine does not denote a propositional operator, but rather an aspectual operator, call it END, that applies to an event $e$ and selects the endpoint of $e, \operatorname{END}(e)$. For example, in the context-sentence in (21) below, the operator END applies to the event $j$ of Maria and Gianni's journey and selects the endpoint of $j$; the result is then combined with the rest of the containing sentence so as to provide a temporal location for the event of Maria and Gianni's finding themselves in China, which is predicated to be contained in $E N D(j)$. An obvious syntactic correlate of this semantic property of temporal alla fine is that it can take an overt PP complement, as in alla fine della riunione 'at the end of the meeting', although this complement is often omitted by ellipsis in naturally-occurring examples. Furthermore, with or without a PP complement, temporal alla fine may either be used as a stand-

\footnotetext{
${ }^{20}$ In diachronic corpora of Portuguese it is possible to find examples in which afinal has a temporal value akin to the interpretation of alla fine described in this section (Lopes 2011: 132-133).
} 
alone answer to a when-question, as shown in (21a), or be clefted, as in (21b), and it may also be modified by focus adverbs like solo 'only' and quasi 'almost', as shown in (22). ${ }^{21}$

(21) [Context-sentence: Maria e Gianni sono partiti per un lungo viaggio. Alla fine si ritroveranno in Cina. 'Maria and Gianni left for a long journey. At the end they'll find themselves in China.']

a. Q: Quando si ritroveranno in Cina?

'When will they find themselves in China?'

A: Alla fine (del loro viaggio).

'At the end (of their journey).'

b. $\quad$ È alla fine (del loro viaggio) che si ritroveranno in Cina.

'It's at the end (of their journey) that they'll find themselves in China.'

(22) Si ritroveranno in Cina solo/quasi alla fine (del loro viaggio).

'They'll find themselves in China only/almost at the end (of their journey).'

This behavior clearly differentiates temporal alla fine from the propositional operator of $\sim \mathrm{TP}$ that we are concerned with. ${ }^{22}$ Indeed, it is not possible to form a when-question or a cleft sentence from (3b) by extracting alla fine, as shown in (23a,b):

${ }^{21}$ In the following naturally-occurring examples showing the modification of temporal alla fine by focusing adverbs, an implicit event-argument is contextually retrieved for the aspectual operator denoted by alla fine, as made explicit in the English glosses:

(i) Proviamo a vincerle tutte e vedremo. Solo alla fine si saprà se sarà stata una stagione di successo o no.

'Let's try to win all the matches and then we'll see. Only in the end [of the championship] will we know if it was a successful season.’

(http://www.laroma24.it/rubriche/la-penna-degli-altri/2014/03/carica-garcia-i-conti-li-faccio-solo-allafine/)

(ii) Il mio è un infortunio lungo e siamo quasi alla fine.

'My injury is a difficult one and we are almost at the end [of the healing period].'

(http://www.corrieredellosport.it/calcio/serie_a/milan/2014/09/29-

378316/Montolivo\%3A+\%C2\%ABSono+quasi+pronto+per+tornare+in+campo\%C2\%BB?print)

22 Some of the syntactic tests that we apply here to differentiate alla fine as a temporal adverb from the same expression as a marker of TP are used by Lopes (2011) to show that afinal in contemporary EP is not a temporal (circumstantial) adverb; unlike adverbs of the latter kind, afinal cannot occur in contexts that require focus to be placed upon it (Lopes 2011: 134). 
(23) [Context sentence: Alla fine vado al cinema questa sera. (= (3b))]
a. Q: *Quando vai al cinema questa sera? A: *Alla fine.
b. $\quad *$ È alla fine che vado al cinema questa sera.

Moreover, it is not possible to modify alla fine in (3b) with the focus adverbs solo/quasi, as shown by the unacceptability of (24):

*Solo/Quasi alla fine vado al cinema questa sera.

To see now that it is temporal alla fine that is involved in (19), we need first to provide a non-negative substitute for the negative sentence containing alla fine in (19). This is because the presence of negation would make it odd to ask the question Quando non si è giunti a nessuna decisione strategica? 'When was no strategic decision reached?', and similarly the modified sentences Solo/Quasi alla fine non si è giunti a nessuna decisione strategica 'Only/Almost at the end was no strategic decision reached'. Thus, consider the variant of (19) in (19'):

(19') I ministri hanno discusso per ore sulla utilizzazione e la destinazione dei fondi della Unione Europea. Da un lato, chi li voleva tutti trasferiti a vantaggio dei consumatori e delle imprese. Dal lato opposto, chi li voleva requisire a favore del contenimento del disavanzo pubblico. In mezzo, chi era per una soluzione mista. Alla fine si è giunti a una decisione strategica provvisoria.

'The ministers have debated for hours about what to do with the EU funds. On the one hand, some wanted to use them all in the interest of customers and companies. On the other hand, others wanted to use them to reduce the public debt. In the middle, yet others were for a mixed solution. Alla fine a provisional strategic decision was reached.'

The morphosyntactic tests that we have applied above converge in showing that it is temporal alla fine that is involved in (19') and hence, in (19), since alla fine has the same interpretation in both contexts. This is shown in (25) and (26): 
(25) a. Q: Quando si è giunti a una decisione strategica provvisoria?

'When did they reach a provisional strategic decision?'

A: Alla fine (della riunione).

'At the end (of the meeting).'

b. $\quad$ È alla fine (della riunione) che si è giunti a una decisione strategica provvisoria.

'It's at the end (of the meeting) that they reached a provisional strategic decision.'

(26) Si è giunti a una decisione strategica provvisoria solo/quasi alla fine (della riunione).

'They reached a provisional strategic decision only/almost at the end (of the meeting).'

Interestingly, the examples containing a narration of a sequence of events allow for an inferential link with the $\sim \mathrm{TP}$ value. In (19), the presence of a temporal process may overlap with a change in the beliefs of some agent: through the discussion of the various points of view among the ministers, different opinions are successively considered, each one pointing to the possibility of reaching a strategic decision concerning the use of the money. Thus, one may infer that before the conclusion of the debate there was an expectation that a strategic decision would be reached. Alla fine then selects the endpoint of the temporal process corresponding to the discussion. This point is characterized by the sentence introduced by alla fine as one at which the expected to be true proposition - the proposition $p^{*}$ that a strategic decision would be reachedturns out to be false. In other terms, the sentence containing alla fine can be contextually associated with $\sim$ TP of $p^{*}$. At a more general level, when a speaker mentions something as obtaining at the end of a temporal sequence (which may be associated to a certain expectation, like the possibility of the ministers reaching a decision, in this case), this mention is justifiedand highly informative-if there is a change, i.e. if the event or situation described is somehow incompatible with a previous expectation.

The temporal value of alla fine analyzed in this section allows us to make an important point concerning the difference between EP and Italian, which is a rationale for comparing these languages with respect to the way they encode truth unpersistence. While the particles afinal and alla fine are cognates and can often be used in similar contexts, only EP has grammaticalized afinal as an epistemic marker, and it has no fim as a temporal adverbial. On the other hand, Italian alla fine displays both epistemic and temporal uses. One can hypothesize that there is a 
historical connection between the epistemic and the temporal meaning: epistemic interpretations of temporal expressions are well attested across languages, and a path leading from temporal interpretations to modal interpretations has been identified in diachronic studies (cf. Traugott and Dasher 2002). Although we do not claim that the analysis provided below will necessarily extend to other languages, we believe that the case of EP and Italian underlies the complexities of the relation between the notions of epistemic modality and temporality. Different languages encode these notions differently, and the specific constraints displayed by the particles are sometimes the result of processes of semantic change with different outcomes across languages. EP and Italian represent two possible choices in the partition of the epistemic and temporal domains. Hence, it should not be surprising to find languages in which particles including the meaning of 'end' pattern like EP afinal and others in which such particles pattern like Italian alla fine. ${ }^{23}$

To conclude, while alla fine on its temporal interpretation 'at the end of $\mathrm{X}$ ' takes an explicit argument denoting a time interval (at the underlying syntactic level which is relevant for the semantic composition), afinal and alla fine as markers of $\sim$ TP do not take any such argument. However, we have already seen that the interpretation of sentences containing these particles is sensitive to a succession of epistemic states, thus it is still required that a time interval be contextually available as an evaluation parameter. The epistemic states referred to by the sentence containing afinal/alla fine are ordered according to the ordering of the time points in this interval, and the final state can thus be identified as the state obtaining at the last point in the interval. We will formalize this idea in section 5 by assuming that the denotation function $[[\cdot]]$ is relativized to a time interval parameter $\mathrm{T}^{*}$.

\section{Previous accounts}

To our knowledge, the only previous analysis that is directly relevant to our present study is proposed by Lopes (2011) in a study of the uses of afinal in European Portuguese. Although our analysis differs from the proposal put forward by Lopes, ${ }^{24}$ it is nevertheless close in spirit to

\footnotetext{
${ }^{23}$ An anonymous reviewer points out that French displays a similar distinction between au final (which, like EP afinal, was grammaticalized as an epistemic) and à la fin (which, like no fim, retains a temporal meaning), but also that au final, like Italian alla fine and unlike EP afinal, may be licensed in contexts that allow for a temporal interpretation based on a temporal sequence, like example (19). We leave the analysis of the French data for future research.

${ }^{24}$ Lopes focuses on the relation between the historically prior temporal value of afinal, in which the adverb introduced the final stage of a temporal sequence of events, and the contemporary non-temporal values that are revealed by its discourse uses, The main hypothesis presented in her paper, within a cognitive-functional
} 
some of Lopes' insights concerning what she calls "valeur de contre-attente" of afinal (“contrastive value”, for short).

Lopes proposes that afinal in its contrastive value is a presuppositional trigger: it presupposes a proposition $p_{1}$, which may be implicit or explicit in the discourse context, and introduces a proposition $p_{2}$ of contrasting polarity, which denies $p_{1}$. Proposition $p_{1}$ is said to be the object of a previous expectation or belief ("une attente (ou croyance) préalable”), as made apparent by the possibility of paraphrasing the sentence expressing $p_{1}$ in naturally occurring data with a propositional attitude verb like 'to think/to expect'. Lopes reports example (27a) (from the newspaper corpus CETEMPúblico), for which she proposes the paraphrase (27b):

(27) a. Quando se previa uma reunião agitada, a assembleia geral ordinária da Federação Portuguesa de Râguebi (...) afinal decorreu na “paz dos anjos”.

'When one predicted a stressful meeting, the general assembly of the Portuguese Rugby Association afinal took place in the most peaceful atmosphere.’

b. Previa-se uma reunião agitada, mas afinal a assembleia geral decorreu na paz dos anjos.

'One predicted a stressful meeting, but afinal the assembly took place in the most peaceful atmosphere.'

In the contrastive value, afinal often co-occurs with the adversative mas 'but', as shown in (27b). In this type of context, afinal "renforce l'implicature de contraste ou rupture d'attente activée par mas”.

The author describes what she takes to be a separate value of afinal, called "valeur épistémique”, by which the speaker “souligne la plausibilité épistémique de la proposition [the prejacent], la présentant comme information ou connaissance partagée”. She gives example (27c) as relevant:

perspective, is that the contemporary values of afinal would all have developed from the original temporal value, which is seen as prototypical. 
(27) c. A sua obra (da publicidade à pintura, do cinema à música, sendo produtor do Velvet Underground) provoca sucessivos efeitos de excesso que são, afinal, um excesso de presença do real.

'His work (...) causes successive effects of excess that are afinal an excess of the presence of reality.'

We argue that (27c) might not require a semantic analysis of afinal different from the one needed for $(27 a, b)$. Both cases seem to involve an epistemic interpretation of the adverb. More to the point, the context of (27c) does not contain clues that bring one to exclude that the adverb has a TP interpretation in this example. We don't share Lopes' intuition that the prejacent of afinal is presented as shared information here; it seems at least coherent with the interpretation of (27c) that the prejacent (the proposition that the successive effects are due to an excess of presence of reality) is presented as new information that defeats a proposition previously regarded as plausible.

Lopes also identifies an interesting use of afinal in interrogative sentences, exemplified in (27d):

d. O açúcar afinal é preciso ou não?

The sugar afinal is needed or not

'Afinal is the sugar needed or not?'

The question in (27d) would be felicitous in a context in which speaker and hearer have been engaged in a conversation (and presumably an activity) involving the possible use of sugar, and in which this possibility is in the common ground of the interlocutors. Such a scenario is compatible with the description provided by Lopes for this value of afinal. According to the author, this use is "adéquat dans un contexte de dispute ouverte prolongée... Il implicite des échanges préalables non convergentes sur le thème” (p. 137). Although the author does not explicitly develop this proposal, the cited passage is reminiscent of the conditions we have identified in sections 2.1 and 2.2 above for the felicitous use of afinal and alla fine. In particular, (27d) may be dealt with along similar lines as the example in (18) above involving a question under discussion: the interlocutors have been considering the alternative possibilities $p_{1}=$ "the 
sugar is needed" vs. $p_{2}=$ "the sugar is not needed" - what may have taken the form of entertaining the modal propositions that the sugar may (not) be needed. By uttering (27d), the speaker asks which of the two defeats occurs: (i) $p_{1}$ obtains, hence defeating the previously entertained proposition that the sugar may not be needed, or (ii) $p_{2}$ obtains, hence defeating the previously entertained proposition that the sugar may be needed.

In conclusion, we find that Lopes’ proposal has two limitations. First, Lopes claims that afinal in the contrastive value does not modify a proposition (hence, presumably, it is not analyzable as a propositional operator). The reason she adduces for this claim is that it is rather a presuppositional trigger establishing a relation of contrast between two propositions-a local proposition (the prejacent) and another, usually implicit, proposition (Lopes 2011: 135). We disagree with the author on this point: on our analysis, afinal is a propositional operator, just as modal adverbs like maybe, possibly, necessarily, etc. in classical possible world analyses, and it just turns out that it is a presuppositional one, namely it only accepts propositions as arguments that are in a relation of "contrast" with some backgrounded proposition $p^{*}$. The fact that the interpretation of $\operatorname{afinal}(p)$ in context involves reference to a proposition $p^{*} \neq p$ does not invalidate or make impossible an analysis in which afinal primarily operates on the prejacent $p$, as we will show in section 5. Second, we consider that the contrastive value is also an epistemic value, since the contrast established by afinal is one between two epistemic attitudes of an agent, not a polarity contrast between two propositions conceived with respect to an objective notion of propositional truth. Crucially, it is striking that Lopes does not establish this connection, as the author states that the proposition prejacent to afinal is presented as being "certain”, hence contrasting in epistemic value with the presupposed proposition. Finally, it is unclear why the occurrence of afinal in the interrogative (27d) should be treated separately. It seems to instantiate the specific discourse conditions for the use of afinal that we described in section 2 above, and we have shown how it could be subsumed under our analysis.

\section{Analysis of the data}

In this section, we propose a formal analysis of the meaning of afinal/alla fine as modal operators of $\sim \mathrm{TP}$. 


\subsection{The model}

We assume a model structure $\mathrm{M}=<\left\{\mathcal{G}_{i}\right\}, \mathrm{T}, \leq_{\mathrm{T}}, \mathrm{W},\left\{\Omega_{<\mathcal{G}, t, w>}\right\},\left\{\mathcal{R}_{<_{\mathcal{G}, t}, \mathrm{w}>}\right\}>$, defined as follows:

(a) $\quad\left\{\mathcal{G}_{i}\right\}$ is a set of sets $\mathcal{G}_{i}$ of epistemic agents;

(b) $\mathrm{T}$ is a non-empty set, the set of times;

(c) $\leq_{\mathrm{T}}$, is a linear order on $\mathrm{T}$, the relation of succession between times;

(d) $\mathrm{W}$ is a non-empty set, the set of possible situations, which includes possible worlds (i.e., maximal situations);

(e) $\quad\left\{\Omega_{<\mathcal{G}, t, w>}\right\}$ is a family of sets $\Omega_{<\mathcal{G}, t, w>} \in \wp(\mathrm{W})$ such that $\mathcal{G} \in\left\{\mathcal{G}_{i}\right\}, t \in \mathrm{T}, w \in \mathrm{W}$ and the worlds $w^{\prime} \in \Omega_{<\mathcal{G}, t, w>}$ are the worlds compatible with the propositions that the epistemic agents in $\mathcal{G}$ accept as true at time $t$ in world $w$ —we call $\Omega_{<\mathcal{G}, t, w>}$ the epistemic state of the set of agents $\mathcal{G}$ at time $t$ in world $w$;

(f) $\quad\left\{\mathcal{R}_{<\mathcal{G}, t, w>}\right\}$ is a family of partial relations $\mathcal{R}_{<\mathcal{G}, t, w>}$ over possible worlds, such that $\mathcal{G} \in$ $\left\{\mathcal{G}_{i}\right\}, t \in \mathrm{T}, w \in \mathrm{W}$ and the domain over which $\mathcal{R}_{<\mathcal{G}, t, w>}$ is defined is the epistemic state $\Omega_{<\mathcal{G}, t, w>} ; \mathcal{R}_{<\mathcal{G}, t, w>}$ is a partial order over $\Omega_{<\mathcal{G}, t, w>}$ such that $\mathcal{R}_{<\mathcal{G}, t, w>}\left(w_{2}, w_{3}\right)$ if and only if $w_{2}$ is more likely than $w_{3}$ for $\mathcal{G}$ at $t$ in $w$.

The epistemic state of $\mathcal{G}$ at $t$ may differ from the epistemic state of $\mathcal{G}$ at a subsequent $t^{\prime}$, as knowledge about past facts and epistemic attitudes toward the future in $\mathcal{G}$ evolve. A crucial assumption concerns epistemic change: as new information $p$ is accepted by members of $\mathcal{G}$ at time $t+1$, the previous epistemic state $\Omega_{<\mathcal{G}, t, w>}$ is updated by adding $p$ to it. However, the update from $\Omega_{<\mathcal{G}, t, w>}$ to $\Omega_{<\mathcal{G}, t+1, w>}$ need not be such that there are possibilities $w_{i}, \ldots w_{j} \in \Omega_{<\mathcal{G}, t, w>}$ that are eliminated tout court in the passage to $\Omega_{<\mathcal{G}, t+1, w>}{ }^{25}$ Rather, we allow for the case in which the

\footnotetext{
${ }^{25}$ In classical theories of contextual update (Stalnaker 1978), such possibilities $w_{i}, \ldots, w_{j}$ are the worlds in which the proposition representing the incoming information is false. An anonymous reviewer points out that a notion of belief
} 
new information makes previously entertained possibilities unlikely, without bringing about their outright elimination. The possibilities at stake will survive in passing from a state $\Omega_{<\mathcal{G}, t, w>}$ to a

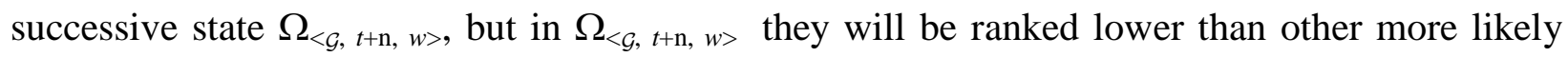
possibilities according to the ordering relation $\mathcal{R}_{<\mathcal{G}, t+n, w>}$.

We assume that linguistic expressions are mapped onto their semantic values via a denotation function [[ - ] which is relativized to evaluation parameters, including a context parameter $C$ and a world parameter $w$. We allow for the evaluation parameters on [[ $\cdot]$ to include a time interval parameter $T^{*}$, which represents the contextually salient set of times that is relevant for the interpretation of an utterance of afinal/alla fine $(p)$.

A fundamental assumption that we make is that propositions are temporally specific, namely they are functions from possible worlds to truth values and they do not take a time argument. To illustrate this point, consider the following example from Italian. ${ }^{26}$ Suppose that on Friday, May $22^{\text {nd }} 2015$ I tell you (28):

(28) Andiamo al mare domenica.

'We're going to the sea on Sunday.'

On the Sunday in question there happen to be rains everywhere in the country. I see you again on Monday and I tell you (29):

(29) Alla fine non siamo andati al mare domenica.

'Alla fine we gave up our plan to go to the sea on Sunday.'

Although the proposition in (28) is in the present tense and the prejacent of alla fine in (29) is in the past tense, the latter is the negation of the former, given the contexts in which (28) and (29) are uttered. In other words, the proposition in (28) and the one which is negated in (29) are the

update and revision akin to our notion of epistemic change has been proposed within dynamic theories of preferential upgrade (e.g. Baltag and Smets 2008). A related proposal in which the reliability of sources is connected to a knowledge update is made by McCready (2014), who establishes a connection between evidentiality and information update.

${ }^{26}$ The choice of language is not relevant here - the same point could be illustrated by taking an example from EP. 
same temporally specific proposition: the one that is true in a world $w$ if and only if we go to the sea on Sunday, May 24th 2015 in w. On this view, the utterances of (28) and (29) differ grammatically in spite of involving the same proposition $p$, because they are differently located with respect to the state of affairs described by $p$. The fact that these two utterances involve the same proposition explains how alla fine in (29) can express $\sim \mathrm{TP}$ of a proposition which is in fact old, in spite of the grammatical differences in the expression.

\subsection{Analysis of the meaning of afinal/alla fine}

We use partial functions as a formal tool to capture the contextual effects described in section $2^{27}$

(

$\lambda x: \phi[x] . \psi[x]$ is the function $f$ such that:

i. $\quad f$ is defined for an object $x$ if and only if the definedness condition $\phi$ is satisfied;

ii. if defined for $x, f$ assigns to $x$ whatever value is described by $\psi$.

The application of a partial function $\lambda x: \phi[x] . \psi[x]$ to an object $a$ yields the value $\{\phi[a]\} \psi[a]$. The formula $\{\phi[a]\} \psi[a]$ is equivalent to $\psi[a]$, provided that the definedness condition $\phi[a]$ is satisfied. If the definedness condition is not satisfied, $\{\phi[a]\} \psi[a]$ is undefined. Note that interpreting afinal/alla fine in terms of a partial function is compatible with an account of sentences like (17) in terms of accommodation; the idea, very simply, is that the definedness condition $\phi[x]$ can be evaluated after the accommodation of the missing piece of information has taken place. For an utterance of $\operatorname{afinal}(p)$, this guarantees that the proposition thereby expressed can be evaluated as true or false even in cases like (17), in which the presuppositional antecedent $p^{*}$ is not initially available in the common ground.

To analyze the meaning of afinal/alla fine, we use a partial function whose admissible arguments are constrained by a context-sensitive definedness condition. We model (in)felicity of

\footnotetext{
${ }^{27}$ Nothing essential in our proposal hinges on the choice of this particular implementation. The reader is referred to Van der Sandt (1992) and Beaver (2001) for other options to implement the presuppositional component of these particles.
} 
an utterance of sentence $S$ in context $C$ as (un)definedness of the semantic value of $S$ relative to $C$ and to the world of evaluation set up by $C$. Given the assumptions above, we propose the following lexical entry for afinal/alla fine (where $C$ is the context of utterance, $\mathrm{T}^{*}$ is the contextually salient time interval that is relevant for the interpretation of afinal/alla fine( $p)$, $w_{0}$ is the world of evaluation, $\operatorname{int}(C) / \operatorname{sp}(C)$ are the interlocutors/speaker of $C, K_{\mathrm{X}}(p)$ means that the agent(s) X know(s) the proposition $p$ ):

$$
\begin{aligned}
\text { [[ afinal/alla fine }]]^{C, \mathrm{~T}^{*}, w 0=} & \lambda p: \exists p^{*} \exists \mathcal{G}^{*} \exists t_{1} \in \mathrm{T}^{*}\left[t_{1} \leq_{\mathrm{T}} \operatorname{END}\left(\mathrm{T}^{*}\right) \wedge K_{\text {int }(C)}\left(\Omega_{<\mathcal{G}^{*}, t 1, w 0>\subseteq}\right.\right. \\
& \left.\left.p^{*}\right) \wedge p^{*} \cap p=\varnothing\right] . p\left(w_{0}\right)=1 \& \forall w_{3}\left[\left[w_{3} \in \Omega_{<s p(\mathrm{C}), E N D\left(\mathrm{~T}^{*}\right),}\right.\right. \\
& w 0>\wedge \neg \exists w_{2}\left[w_{2} \in \Omega_{<s p(\mathrm{C}), E N D\left(\mathrm{~T}^{*}\right), w 0>} \wedge \mathcal{R}_{<s p(C), E N D\left(\mathrm{~T}^{*}\right),}\right. \\
& \left.\left.\left.{ }_{w 0>}\left(w_{2}, w_{3}\right)\right]\right] \rightarrow p\left(w_{3}\right)=1\right]
\end{aligned}
$$

According to (30), relative to a context $C$ and world of evaluation $w_{0}$, afinal denotes a partial function $f$ from propositions to truth values such that:

(a) $\quad f(p)$ is defined only if $p$ is incompatible with a proposition $p^{*}$ which the interlocutors of $C$ know to be the object of the belief or expectation of the epistemic agents in a set $\mathcal{G}^{*}$ at a time $t_{1}$ in the evaluation interval $\mathrm{T}^{*}$ that is before the endpoint of $\mathrm{T}^{*}$;

(b) whenever defined, $f(p)$ is true if $p$ is true at the world of evaluation $w_{0}$ and at all best epistemic worlds accessible for the speaker of $C$ at the endpoint of $\mathrm{T}^{*}$ in the world of evaluation $w_{0}$.

We are providing a complete modal analysis of the meaning of the particles in which modality is not just in the presupposition (definedness condition) but also in the asserted meaning, i.e. we are dealing with the epistemic space in the assertive component of the semantic value too. The purpose of the modal condition in the assertive component is to constrain the set of epistemic worlds over which the particles quantify, as assumed in ordering semantics accounts of modality (e.g. Kratzer 1981, 1991, 2012). 
Importantly, we are not making any particular assumption concerning the set $\mathcal{G}^{*}$ : it may consist of the interlocutors of the immediate context of utterance (i.e., the agents in int $(C)$ ), but it may also be a set of agents whose perspectives on the eventualities referred to in the discourse are relevant. However, the analysis in (30) also makes reference to the interlocutors of the context, as long as it ascribes to them the shared knowledge that the proposition $p^{*}$ characterizes (i.e. is true in all worlds in) the epistemic state of $\mathcal{G}^{*}$ at the time $t_{1} \in \mathrm{T}^{*}$ in the world of evaluation $w_{0}$; furthermore, it refers to the epistemic state of the speaker $\operatorname{sp}(C)$ at the time $\operatorname{END}\left(\mathrm{T}^{*}\right)$ in the world $w_{0}$, by requiring that the prejacent $p$ hold true at all best epistemic worlds accessible for $s p(C)$ at the endpoint of $\mathrm{T}^{*}$ in $w_{0}$.

\subsection{Application of the analysis to previously considered data}

Let's see how the analysis works in the types of cases identified in Section 2.

\subsubsection{Plan-related propositions}

First, consider the case of plan-related prejacents—-we repeat examples (3a,b) and (4a,b) below.

(3) a. Afinal hoje vou ao cinema.

b. Alla fine vado al cinema questa sera.

'Afinal/alla fine I'm going to the movies tonight.'

(4) a. Afinal os Jogos Olímpicos de 2016 não vão ser no Rio de Janeiro

b. Alla fine le Olimpiadi 2016 non si terranno a Rio de Janeiro.

'Alla fine the 2016 Olympics won't take place in Rio de Janeiro.'

The prejacents of afinal/alla fine in (3a,b) and (4a,b), relative to a context of utterance $C$, are the propositions (31) and (32), respectively:

(31) $\quad(\lambda w$. [[ vou ao cinema $\left.]]^{C T^{*}, w}=1\right)=(\lambda w \cdot s p(C)$ goes to the movies on day $d$ in $w)$ 
(32) ( $\lambda w$. [[ os Jogos Olímpicos de 2016 não vão ser no Rio de Janeiro $\left.]]^{\complement T^{*}, w}=1\right)=(\lambda w$. $\sim($ Olympics take place in Rio de Janeiro in 2016 in w))

Propositions (31) and (32) feed the propositional argument of afinal. The results of the functional application are given in (33) and (34) below.

a. $\quad[$ afinal $]]^{C, T^{*}, w 0}(\lambda w$. [[ vou ao cinema $\left.\left.]\right]^{C T^{*}, w}=1\right)=$

b. $\quad\left(\lambda p: \exists p^{*} \exists \mathcal{G}^{*} \exists t_{1} \in \mathrm{T}^{*}\left[t_{1} \leq_{\mathrm{T}} E N D\left(\mathrm{~T}^{*}\right) \wedge K_{\text {int(C) }}\left(\Omega_{<\mathcal{G}^{*}, t 1, w 0>} \subseteq p^{*}\right) \wedge p^{*} \cap p=\varnothing\right]\right.$.

$p\left(w_{0}\right)=1 \wedge \forall w_{3}\left[\left[w_{3} \in \Omega_{<s p(\mathrm{C}), E N D\left(\mathrm{~T}^{*}\right), w 0>} \wedge \neg \exists w_{2}\left[w_{2} \in \Omega_{<s p(\mathrm{C}), E N D\left(\mathrm{~T}^{*}\right), w 0>} \wedge\right.\right.\right.$ $\left.\left.\mathcal{R}_{\left.\left.<s p(C), E N D\left(T^{*}\right), w_{0}>\left(w_{2}, w_{3}\right)\right]\right]} \rightarrow p\left(w_{3}\right)=1\right]\right)(\lambda w . s p(C)$ goes to the movies on day $d$ in $w)=$

c. $\quad\left\{\exists p^{*} \exists \mathcal{G}^{*} \exists t_{1} \in \mathrm{T}^{*}\left[t_{1} \leq_{\mathrm{T}} \operatorname{END}\left(\mathrm{T}^{*}\right) \wedge K_{\text {int }(C)}\left(\Omega_{<\mathcal{G}^{*}, t 1, w 0>} \subseteq p^{*}\right) \wedge p^{*} \cap(\lambda w . s p(C)\right.\right.$ goes to the movies on day $d$ in $w)=\varnothing]\}(\lambda w . s p(C)$ goes to the movies on day $d$ in $w)\left(w_{0}\right)=1 \wedge \forall w_{3}\left[\left[w_{3} \in \Omega_{<s p(C), E N D\left(T^{*}\right), w 0>} \wedge \neg \exists w_{2}\left[w_{2} \in \Omega_{<s p(C), E N D\left(T^{*}\right), w 0>} \wedge\right.\right.\right.$ $\left.\left.\mathcal{R}_{<s p(C), E N D\left(T^{*}\right), w_{0}>}\left(w_{2}, w_{3}\right)\right]\right] \rightarrow(\lambda w . s p(C)$ goes to the movies on day $d$ in $w)\left(w_{3}\right)=$ 1] $=$

d. $\quad\left\{\exists p^{*} \exists \mathcal{G}^{*} \exists t_{1} \in \mathrm{T}^{*}\left[t_{1} \leq_{\mathrm{T}} \operatorname{END}\left(\mathrm{T}^{*}\right) \wedge K_{\text {int(C) }}\left(\Omega_{<\mathcal{G}^{*}, t 1, w 0>} \subseteq p^{*}\right) \wedge p^{*} \cap(\lambda w . s p(C)\right.\right.$ goes to the movies on day $d$ in $w)=\varnothing]\}\left[\operatorname{sp}(C)\right.$ goes to the movies on day $d$ in $\left.w_{0}\right]$ $\wedge \forall w_{3}\left[\left[w_{3} \in \Omega_{<s p(\mathrm{C}), E N D\left(\mathrm{~T}^{*}\right), w 0>} \wedge \neg \exists w_{2}\left[w_{2} \in \Omega_{<s p(\mathrm{C}), E N D\left(\mathrm{~T}^{*}\right), w 0>} \wedge \mathcal{R}_{<s p(\mathrm{C}), E N D\left(\mathrm{~T}^{*}\right),}\right.\right.\right.$ $\left.\left.{ }_{w 0>}\left(w_{2}, w_{3}\right)\right]\right] \rightarrow\left[\operatorname{sp}(C)\right.$ goes to the movies on day $d$ in $\left.\left.w_{3}\right]\right]$

According to (33d):

(A) sentence (3a) is defined in $C$ relative to $w_{0}$ only if there is a (backgrounded) proposition $p^{*}$ and a set of epistemic agents $\mathcal{G}^{*}$ such that the interlocutors of $C$ know that $p^{*}$ characterized the epistemic state of $\mathcal{G}^{*}$ at some time $t_{1}$ in the relevant time interval $\mathrm{T}^{*}$ in 
$w_{0}$, and $p^{*}$ is incompatible with the (prejacent) proposition that the speaker of $C$ goes to the movies on the relevant day;

(B) if defined in $C$ relative to $w_{0}$, (3a) is true in $C$ relative to $w_{0}$ if both:

(i) the speaker (of $C$ ) goes to the movies on the relevant day in $w_{0}$ and (ii) for all best epistemic alternatives $w_{3}$ of the speaker at the endpoint of $T^{*}$ in $w_{0}$, the speaker goes to the movies on the relevant day in $w_{3}$.

Notice that, in this case, the set $\mathcal{G}^{*}$ just consists of the speaker, $p^{*}$ is the old plan of the speaker that she would go to the theater on the relevant day (a plan which she entertained at the time $t_{1}$ preceding the shift of interest to the movie), and $\mathrm{T}^{*}$ is a time interval spanning from $t_{1}$ to the time of utterance.

(34) a. $\quad[[\text { afinal }]]^{\complement T^{*}, w 0}(\lambda w$. [[ os Jogos Olímpicos de 2016 não vão ser no Rio de Janeiro ]$\left.^{C, T^{*}, w}=1\right)=$

b. $\quad\left(\lambda p: \exists p^{*} \exists \mathcal{G}^{*} \exists t_{1} \in \mathrm{T}^{*}\left[t_{1} \leq_{\mathrm{T}} \operatorname{END}\left(\mathrm{T}^{*}\right) \wedge K_{\text {int }(C)}\left(\Omega_{<g^{*}, t 1, w 0>} \subseteq p^{*}\right) \wedge p^{*} \cap p=\varnothing\right]\right.$. $p\left(w_{0}\right)=1 \wedge \forall w_{3}\left[\left[w_{3} \in \Omega_{<s p(\mathrm{C}), E N D\left(\mathrm{~T}^{*}\right), w 0>} \wedge \neg \exists w_{2}\left[w_{2} \in \Omega_{<s p(\mathrm{C}), E N D\left(\mathrm{~T}^{*}\right), w 0>} \wedge\right.\right.\right.$

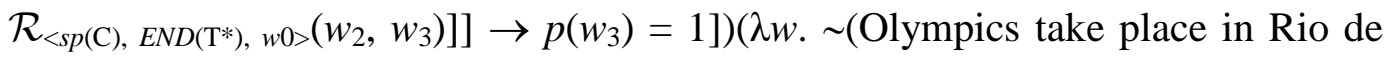
Janeiro in 2016 in $w)$ ) $=$

c. $\quad\left\{\exists p^{*} \exists \mathcal{G}^{*} \exists t_{1} \in \mathrm{T}^{*}\left[t_{1} \leq_{\mathrm{T}} E N D\left(\mathrm{~T}^{*}\right) \wedge K_{\text {int(C) }}\left(\Omega_{<\mathcal{G}^{*}, t 1, w 0>} \subseteq p^{*}\right) \wedge p^{*} \cap \lambda w\right.\right.$. $\sim($ Olympics take place in Rio de Janeiro in 2016 in $w)=\varnothing]\}(\lambda w . \sim($ Olympics take place in Rio de Janeiro in 2016 in $w))\left(w_{0}\right)=1 \wedge \forall w_{3}\left[\left[w_{3} \in \Omega_{<s p(C), E N D\left(T^{*}\right),}\right.\right.$ $w 0>\wedge \neg \exists w_{2}\left[w_{2} \in \Omega_{<s p(C), E N D\left(T^{*}\right), w 0>} \wedge \mathcal{R}_{\left.\left.<s p(C), E N D\left(T^{*}\right), w_{0}>\left(w_{2}, w_{3}\right)\right]\right]} \rightarrow(\lambda w\right.$. $\sim($ Olympics take place in Rio de Janeiro in 2016 in $\left.w))\left(w_{3}\right)=1\right]=$

d. $\quad\left\{\exists p^{*} \exists \mathcal{G}^{*} \exists t_{1} \in \mathrm{T}^{*}\left[t_{1} \leq_{\mathrm{T}} E N D\left(\mathrm{~T}^{*}\right) \wedge K_{\text {int(C) }}\left(\Omega_{<\mathcal{C}^{*}, t 1, w 0>} \subseteq p^{*}\right) \wedge p^{*} \cap \lambda w\right.\right.$. $\sim($ Olympics take place in Rio de Janeiro in 2016 in $w)=\varnothing]\} \sim($ Olympics take place in Rio de Janeiro in 2016 in $\left.w_{0}\right) \wedge \forall w_{3}\left[\left[w_{3} \in \Omega_{<s p(C), E N D\left(\mathrm{~T}^{*}\right), w 0>} \wedge \neg \exists w_{2}\left[w_{2}\right.\right.\right.$ 
$\left.\left.\in \Omega_{<s p(C), E N D\left(T^{*}\right), w 0>} \wedge \mathcal{R}_{<s p(C), E N D\left(T^{*}\right), w 0>}\left(w_{2}, w_{3}\right)\right]\right] \rightarrow \sim($ Olympics take place in Rio de Janeiro in 2016 in $w_{3}$ )]

According to (34d):

(A) sentence (4a) is defined in $C$ relative to $w_{0}$ only if there is a (backgrounded) proposition $p^{*}$ and a set of epistemic agents $\mathcal{G}^{*}$ such that the interlocutors of $C$ know that $p^{*}$ characterized the epistemic state of $\mathcal{G}^{*}$ at some time $t_{1}$ in the relevant time interval $\mathrm{T}^{*}$ in

$w_{0}$, and $p^{*}$ is incompatible with the (prejacent) proposition that it is not true that the Olympics take place in Rio de Janeiro in 2016;

(B) if defined in $C$ relative to $w_{0}$, (4a) is true in $C$ relative to $w_{0}$ if both:

(i) it is not the case that the Olympics take place in Rio de Janeiro in 2016 in $w_{0}$ and (ii) for all best epistemic alternatives $w_{3}$ of the speaker at the endpoint of $\mathrm{T}^{*}$ in $w_{0}$, it is not the case that the Olympics take place in Rio de Janeiro in 2016 in $w_{3}$.

In this case, the set $\mathcal{G}^{*}$ consists of the members of the International Olympic Committee, $p^{*}$ is the Committee's old plan that the Olympics would take place in Rio de Janeiro in 2016-a plan which was entertained at the time $t_{1}$ preceding the success of the boycott against Rio-and, as for the example (3a), $\mathrm{T}^{*}$ is a time interval spanning from $t_{1}$ to the time of utterance.

\subsubsection{Non plan-related propositions}

We now consider the case of non plan-related prejacents. Let's go back to (7a) (the analysis applies in the same way to Italian [7b]—mutatis mutandis):

(7) a. Afinal o Micha não é russo.

'Afinal/Alla fine Micha is not Russian.' 
The prejacent of afinal in (7a) is the proposition (35), which feeds the propositional argument of afinal to yield the truth conditions (36) (we omit the intermediate passages of the derivation).

(35) $(\lambda w$. [[o Micha não é russo $\left.]]^{\complement T^{*}, w}=1\right)=(\lambda w . \sim($ Micha is Russian in $w))$

$[$ a afinal $]]^{C T^{*}, w 0}(\lambda w$. [[o Micha não é russo $\left.\left.]\right]^{C T^{*}, w}=1\right)=$ $\left\{\exists p^{*} \exists \mathcal{G}^{*} \exists t_{1} \in \mathrm{T}^{*}\left[t_{1} \leq_{\mathrm{T}} \operatorname{END}\left(\mathrm{T}^{*}\right) \wedge K_{\text {int(C) }}\left(\Omega_{<\mathcal{G}^{*}, t 1, w 0>} \subseteq p^{*}\right) \wedge p^{*} \cap(\lambda w . \sim(\right.\right.$ Micha is Russian in $w))=\varnothing]\} \sim\left(\right.$ Micha is Russian in $\left.w_{0}\right) \wedge \forall w_{3}\left[\left[w_{3} \in \Omega_{<s p(\mathrm{C}), E N D\left(T^{*}\right), w 0>} \wedge \neg \exists w_{2}\right.\right.$ $\left.\left[w_{2} \in \Omega_{<p p(\mathrm{C}), E N D\left(\mathrm{~T}^{*}\right), w 0>} \wedge \mathcal{R}_{<p p(\mathrm{C}), E N D\left(\mathrm{~T}^{*}\right), w 0>}\left(w_{2}, w_{3}\right)\right]\right] \rightarrow \sim\left(\right.$ Micha is Russian in $\left.\left.w_{3}\right)\right]$

According to (36):

(A) sentence (7a) is defined in $C$ relative to $w_{0}$ only if there is a (backgrounded) proposition $p^{*}$ and a set of epistemic agents $\mathcal{G}^{*}$ such that the interlocutors of $C$ know that $p^{*}$ characterized the epistemic state of $\mathcal{G}^{*}$ at some time $t_{1}$ in the relevant time interval $\mathrm{T}^{*}$ in $w_{0}$, and $p^{*}$ is incompatible with the (prejacent) proposition that it is not true that Micha is Russian;

(B) if defined in $C$ relative to $w_{0},(7 a)$ is true in $C$ relative to $w_{0}$ if both:

(i) it is not the case that Micha is Russian in $w_{0}$ and (ii) for all best epistemic alternatives $w_{3}$ of the speaker at the endpoint of $\mathrm{T}^{*}$ in $w_{0}$, it is not the case that Micha is Russian in $w_{3}$.

Given the context described in section 2.2 for the utterance of $(7 \mathrm{a}, \mathrm{b})$, it is clear that the set $\mathcal{G}^{*}$ consists of the speaker and the hearer, while $p^{*}$ is their old belief that Micha is Russian and $\mathrm{T}^{*}$ is an interval spanning from the time when this old belief was formed to the present.

Summing up, we have proposed an analysis in which afinal and alla fine are treated as (almost) standard modal operators: like standard modal operators, they apply to a proposition and yield a truth value, but unlike such operators, they also have definedness conditions relating to the status of their propositional argument with respect to discourse information. 


\subsubsection{Questions under discussion}

Finally, let's consider the case in which a question is under discussion before the epistemic change marked by alla fine/afinal takes place. One relevant example we discussed is (18), repeated here (along with the description of its context).

(18) [Context. A family has considered a number of alternative plans for vacation: going to the seaside, going to the mountains, and going to Rome. After debating the issue, they choose going to the seaside.]

Alla fine quest'estate andiamo al mare.

'Alla fine, this summer we go to the seaside.'

The prejacent of alla fine, relative to the context $C$ described above, is the proposition (37):

(37) $(\lambda w$. [[ quest'estate andiamo al mare $\left.]]^{C T^{*}, w}=1\right)=(\lambda w$. the $C$-relevant family goes to the seaside the next summer of $C$ in $w$ )

Proposition (37) feeds the propositional argument of afinal, and this functional application yields (38):

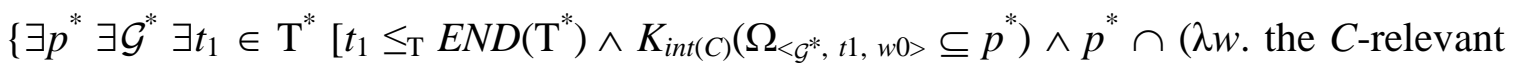
family goes to the seaside the next summer of $C$ in $w$ ) $=\varnothing]\}$ [the $C$-relevant family goes to the seaside the next summer of $C$ in $\left.w_{0}\right] \wedge \forall w_{3}\left[\left[w_{3} \in \Omega_{<s p(C), E N D\left(T^{*}\right), w 0>} \wedge \neg \exists w_{2}\left[w_{2} \in\right.\right.\right.$ $\left.\left.\Omega_{<s p(C), E N D\left(T^{*}\right), w 0>} \wedge \mathcal{R}_{\left\langle p p(C), E N D\left(T^{*}\right), w 0>\right.}\left(w_{2}, w_{3}\right)\right]\right] \rightarrow$ [the $C$-relevant family goes to the seaside the next summer of $C$ in $\left.\left.w_{3}\right]\right]$

According to (38):

(A) sentence (18) is defined in $C$ relative to $w_{0}$ only if there is a (backgrounded) proposition $p^{*}$ and a set of epistemic agents $\mathcal{G}^{*}$ such that the interlocutors of $C$ know that $p^{*}$ 
characterized the epistemic state of $\mathcal{G}^{*}$ at some time $t_{1}$ in the relevant time interval $\mathrm{T}^{*}$ in $w_{0}$, and $p^{*}$ is incompatible with the (prejacent) proposition that the C-relevant family goes to the seaside the next summer of $C$;

(B) if defined in $C$ relative to $w_{0}$, (18) is true in $C$ relative to $w_{0}$ if both:

(i) the $C$-relevant family goes to the seaside the next summer of $C$ in $w_{0}$ and (ii) for all best epistemic alternatives $w_{3}$ of the speaker at the endpoint of $T^{*}$ in $w_{0}$, the $C$-relevant family goes to the seaside the next summer of $C$ in $w_{3}$.

As suggested in section 2.4, the epistemic state of the $C$-relevant family at the time at which the question where to go for vacation is entertained may be associated with the modal proposition $\diamond \mathrm{R}=$ that the C-relevant family may go to Rome the next summer of $C$, which is defeated by the prejacent of (18). The solution that we propose to the problem raised by (18) consists in assuming that proposition $p^{*}=\diamond \mathrm{R}$.

\section{Conclusion}

In this paper, we have provided a semantic analysis of afinal and alla fine that relies on two main assumptions: (i) the particles denote a modal operator, and (ii) they trigger specific presuppositions in that they impose conditions of use regarding the shared conversational background of the interlocutors. By looking at the occurrence of alla fine/afinal in a range of naturally-occurring examples, two cases have been identified: one in which there is a planrelated proposition, and one in which there is no plan-related proposition. We have shown that in both cases the felicitous use of the particles requires an epistemic change of some agents regarding the truth of a proposition incompatible with the prejacent. This change occurs at a time that is the endpoint of a time interval relevant for the interpretation of the particles. We have also considered a third case, in which a question under discussion is shared by the interlocutors and several possible alternative propositions are entertained before the epistemic change occurs. The detailed analysis of the naturally-occurring data, with reference to their contexts, has made it possible to recognize the discourse structures that license the use of alla fine/afinal—discourse structures that we had previously identified by reasoning on constructed examples-while at the same time exploring the semantic value of particles that also incorporate a modal component. To 
our knowledge, such an explicit account of the semantics of modal particles that integrates discourse constraints is new in the literature.

The proposed concept of unpersistence pertaining to the domain of propositional truth shows that epistemic modality may at times be deeply interconnected with discourse structure; a sentence of the form afinal(S), expressing truth unpersistence, encodes epistemic change and can felicitously occur only in particular discourse contexts. In this connection, our proposal relates to previous work carried out in dynamic semantics, which bears on the connection between epistemic modality and discourse sequences (in particular, Veltman’s 1996 by now classical work on the English epistemic modal might in Update Semantics). Although the connection between epistemic modals and discourse update is not new, this paper brings new data to the theoretical discussion. In particular, it adds further complexities to the extensively studied epistemic modal might, since afinal and alla fine make reference both to multiple points in time and to the epistemic attitudes entertained by multiple agents at those times. An advantage of our analysis is that it connects temporality and epistemic modality; regardless of the tense of the sentence, what uniquely matters for the interpretation of afinal and alla fine is the ordering relation between the time points in the relevant subset of times (i.e. $\mathrm{T}^{*}$ ) and the order it induces on epistemic states and their evaluation.

Yet another issue raised in this paper is the connection between epistemic modality and evidentiality. As Kratzer (2012) puts it, “Cross-linguistically, the invariant job of an evidential is to classify evidence for what is being said as direct, indirect, or hearsay [...]. The crosslinguistically invariant job of an epistemic modal is [...] to assess the truth of a proposition against a range of possibilities projected from a body of evidence. There are two distinct semantic jobs to be done, then [...]. The two jobs often end up being carried by a single portmanteau item that might then be arbitrarily cataloged as modal or evidential.” Our data show that while afinal allows for evidential inferences, it is not strictly speaking an evidential, if we adopt the definition of evidentials given by Kratzer in the quoted passage. Indeed, afinal does not encode a classification of evidence as direct, indirect, or hearsay, but only indicates that an epistemic change has taken place. The semantics that we have formalized in section 5 does capture this property, since it makes no reference to types of evidence but only to epistemic states, and it only requires that the truth of the prejacent be assessed against a range of possibilities coming from successive epistemic states. However, the examples discussed in 
section 2.2 ("Propositions without plans") show that a change in the belief state of an epistemic agent may indeed trigger inferences to the effect that the source of evidence underlying the most recent belief is direct, since more reliable. This connection between evidentiality and information update has also been recently made (McCready 2014). For instance, in example (7a), repeated here,

Afinal o Micha não é russo.

the change in truth value from false to true for the prejacent proposition (that Micha is not Russian) comes about as a consequence of new evidence, and the truth of this proposition is assessed against a new range of possibilities projected from this new evidence. In this respect, the data presented show that it is often difficult to disentangle epistemic modal notions from evidentiality when we consider a fine-grained analysis of the values of a lexical item, as the consideration of truth values of a proposition is often associated with the source of information and its reliability. Furthermore, these evidential inferences are triggered under specific contextual conditions, i.e. as a result of a succession of epistemic states that are shared by the interlocutors, thus showing the close connection of these meaning components to discourse structure.

Finally, by introducing a time interval parameter $\mathrm{T}^{*}$ to which the truth conditional evaluation of afinal/alla fine $(p)$ is sensitive, with the endpoint of $\mathrm{T}^{*}$ showing up in the assertive component of the semantics, we open up the possibility of a connection both to a historical account of the origin of afinal/alla fine as $\sim \mathrm{TP}$ markers and to a cross-linguistic generalization. Given the semantics we have proposed, we predict that what is now a definedness condition on the partial function which is the semantic value of afinal/alla fine was originally a contextual implication of the utterances containing these particles. Over time, this implication would become semantically encoded. The diachronic facts alluded to by Lopes (2011) for EP afinal point to the existence of this path, whereby from the temporal uses of afinal the ordering of times induced an ordering of epistemic states and this eventually became encoded in the semantics of the particle. The conventionalization of implications regularly associated with a certain form in its contexts of use is consistent with well-established theories of semantic change (e.g. Traugott and Dasher 2002, Eckardt 2006). Furthermore, this account also explains the cross-linguistic 
tendency for items including an element with the meaning of 'end' to develop into modal expressions denoting truth unpersistence. 


\section{References}

Amaral, Patrícia and Fabio Del Prete. 2014. On Truth Persistence: A comparison between European Portuguese and Italian in relation to sempre. In: Marie-Hélène Côté and Eric Mathieu (eds.), Variation within and across Romance Languages. Selected papers from the 41st Linguistic Symposium on Romance Languages, 135-154. Amsterdam: John Benjamins.

Baltag, Alexandru and Sonja Smets. 2008. Probabilistic dynamic belief revision. Synthese 165(2): 179-202.

Baroni, Marco, Silvia Bernardini, Federica Comastri, Lorenzo Piccioni, Alessandra Volpi, Guy Aston, Marco Mazzoleni. 2004. Introducing the "la Repubblica" corpus: A large, annotated, TEI(XML)-compliant corpus of newspaper Italian. In: Proceedings of LREC 2004.

Beaver, David I. 2001. Presupposition and Assertion in Dynamic Semantics. CSLI Publications.

Brito, Ana Maria. 2001. Clause structure, subject positions and verb movement. About the position of sempre in European Portuguese and Brazilian Portuguese. In: D’hulst, Yves, Johan Rooryck and Jan Schroten (eds.), Romance Languages and Linguistic Theory 1999. Selected papers from 'Going Romance’ 1999, John Benjamins.

Ducrot, Oswald. 1984. Le dire et le dit. Paris: Les Editions de Minuit.

Eckardt, Regine. 2006. Meaning Change in Grammaticalization. An Enquiry into Semantic Reanalysis. Oxford: Oxford University Press.

Givón, Talmy. 1989. Mind, Code, and Context: Essays in Pragmatics. Hillsdale, NJ: Erlbaum, 1989. Pp. xviii +456 .

Gonzaga, Manuela. 1997. Aspectos da Sintaxe dos Advérbios em Português. M.A. Dissertation, Lisboa: FLUL.

Groenendijk, Jeroen and Floris Roelofsen. 2009. Inquisitive Semantics and Pragmatics. Language, Communication and Rational Agency [LCRA-09], Stanford, USA, May 3031, 2009.

Groenendijk, Jeroen and Martin Stokhof. 1984. Studies on the Semantics of Questions and the Pragmatics of Answers. PhD thesis, University of Amsterdam. 
Hopper, Paul. 1991. On some principles of grammaticization. In: Elizabeth Closs Traugott and Bernd Heine (eds.), Approaches to Grammaticalization, Vol. I. Amsterdam: John Benjamins, 17-36.

Horn, Laurence. 1989. A natural history of negation. Chicago: University of Chicago Press.

Kratzer, Angelika. 1981. The notional category of modality. In: Hans-Jurgen Eikmeyer \& Hannes Rieser (eds.), Words, Worlds, and Contexts, 38-74. Berlin: de Gruyter.

Kratzer, Angelika. 1991. Modality. In: Arnim von Stechow \& Dieter Wunderlich (eds.), Semantik/semantics: An International Handbook of Contemporary Research, 639-650. Berlin: de Gruyter.

Kratzer, Angelika. 2012. Modals and Conditionals. Oxford University Press.

Lopes, Ana C. M. 2011. La polyfonctionnalité du marqueur discursif 'afinal' en portugais européen. In: E. Khachaturyan (ed.), Discourse markers in Romance languages, Oslo Studies in Language 3(1): 131-140. (ISSN 1890-9639)

McCready, Eric. 2014. Reliability in Pragmatics. Oxford: Oxford University Press.

Santos, Diana and Paulo Rocha. 2001. Evaluating CETEMPúblico, a free resource for Portuguese. In: Proceedings of the 39th Annual Meeting of Association for Computational Linguistics, 450-457.

Spenader, Jennifer. 2002. Presuppositions in spoken discourse. Doctoral Dissertation, Stockholm University, Stockholm.

Stalnaker, Robert. 1974. Pragmatic presuppositions. In: M. Munitz \& P. Unger (eds.), Semantics and Philosophy, 197-213. New York, NY: NYU Press.

Stalnaker, Robert. 1978. Assertion. In: P. Cole (ed.), Pragmatics, Vol. 9, 315-332. New York: New York Academic Press.

Traugott, Elizabeth and Richard Dasher. 2002. Regularity in semantic change. Cambridge: Cambridge University Press.

Van der Sandt, Rob A. 1992. Presupposition Projection as Anaphora Resolution. Journal of Semantics 9(4): 333-377.

Veltman, Frank. 1996. Defaults in Update Semantics. Journal of Philosophical Logic 25(3): 221-261.

Zeevat, Henk. 2009. Only as a mirative particle. Sprache und Datenverarbeitung 33, 179-196. 


\section{Corpora used:}

La Repubblica corpus, a corpus of Italian newspaper text (http://sslmit.unibo.it/repubblica)

CETEMPúblico: Santos, Diana, and Paulo Rocha. CETEMPúblico LDC2001T62. Web Download. Philadelphia: Linguistic Data Consortium, 2001. 